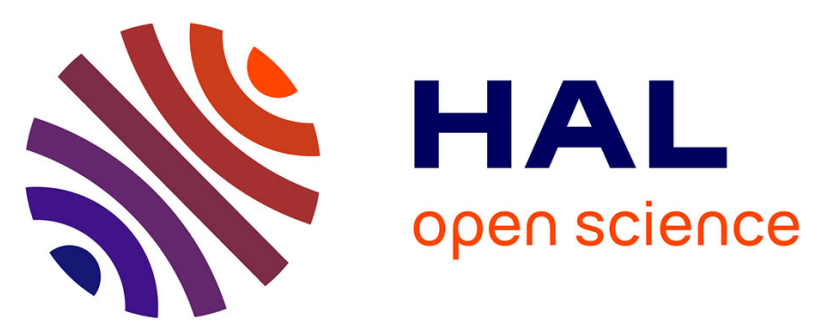

\title{
Two-year survey of specific hospital wastewater treatment and its impact on pharmaceutical discharges
}

Laure Wiest, Teofana Chonova, Alexandre Bergé, Robert Baudot, Frédérique

Bessueille-Barbier, Linda Ayouni-Derouiche, Emmanuelle Vulliet

\section{- To cite this version:}

Laure Wiest, Teofana Chonova, Alexandre Bergé, Robert Baudot, Frédérique Bessueille-Barbier, et al.. Two-year survey of specific hospital wastewater treatment and its impact on pharmaceutical discharges. Environmental Science and Pollution Research, 2018, 25 (10), pp.9207-9218. 10.1007/s11356-0179662-5 . hal-01569749

\author{
HAL Id: hal-01569749 \\ https://hal.science/hal-01569749
}

Submitted on 10 Sep 2020

HAL is a multi-disciplinary open access archive for the deposit and dissemination of scientific research documents, whether they are published or not. The documents may come from teaching and research institutions in France or abroad, or from public or private research centers.
L'archive ouverte pluridisciplinaire HAL, est destinée au dépôt et à la diffusion de documents scientifiques de niveau recherche, publiés ou non, émanant des établissements d'enseignement et de recherche français ou étrangers, des laboratoires publics ou privés. 
1 Two year survey of specific hospital wastewater treatment and its impact on 2 pharmaceutical discharges

3

4 Laure Wiest $^{1 *}$, Teofana Chonova ${ }^{2,3}$, Alexandre Bergé ${ }^{1}$, Robert Baudot ${ }^{1}$, Frédérique 5 Bessueille-Barbier ${ }^{1}$, Linda Ayouni-Derouiche ${ }^{1}$, Emmanuelle Vulliet ${ }^{1}$

$6 \quad{ }^{1}$ Univ Lyon, CNRS, Université Claude Bernard Lyon 1, Ens de Lyon, Institut des Sciences 7 Analytiques, UMR 5280, 5 rue de la Doua, F-69100 VILLEURBANNE, France

$8 \quad{ }^{2}$ Université de Lyon, INSA Lyon, DEEP, F-69621, Villeurbanne Cedex, France

$9{ }^{3}$ GRAIE, Groupe de Recherche Rhône-Alpes sur les Infrastructure et l'Eau, 66 bd Niels Bohr, 10 11 69100 Villeurbanne, France

*Contact : laure.wiest@isa-lyon.fr

\section{Highlights}

- $\quad$ Hospital and urban effluents are compared

- $\quad$ Impact of hospital wastewater on activated sludge treatment is studied

- $\quad$ Seasonal variations of pharmaceuticals removal efficiency are demonstrated

\section{Keywords}

Pharmaceuticals, antibiotics, wastewater treatment, hospital wastewater, removal 


\section{Abstract}

It is well known that pharmaceuticals are not completely removed by conventional activated sludge wastewater treatment plants. Hospital effluents are of major concern as they present high concentrations of pharmaceutically active compounds. Despite this, these specific effluents are usually co-treated with domestic wastewaters. Separate treatment has been recommended. However, there is a lack of information concerning the efficiency of separate hospital wastewater treatment by activated sludge, especially on the removal of pharmaceuticals.

In this context, this article presents the results of a two years monitoring of conventional parameters, surfactants, gadolinium and thirteen pharmaceuticals on the specific study site SIPIBEL. This site allows the characterization of urban and hospital wastewaters and their separate treatment using the same process. Flow proportional sampling, solid phase extraction and liquid chromatography coupled with tandem mass spectrometry were used in order to obtain accurate data and limits of quantification consistent with ultra-traces detection. Thanks to these consolidated data, an in-depth characterization of urban and hospital wastewaters was realized, as well as a comparison of treatment efficiency between both effluents. Higher concentrations of organic carbon, AOX, phosphates, gadolinium, paracetamol, ketoprofen and antibiotics were observed in hospital wastewaters compared to urban wastewaters. Globally higher removals were observed in the hospital wastewater treatment plant and some parameters were shown to be of high importance regarding removal efficiencies: hydraulic retention time, redox conditions and ambient temperature. Eleven pharmaceuticals were still quantified at relevant concentrations in hospital and urban wastewaters after treatment (e.g. up to $1 \mu \mathrm{g} / \mathrm{L}$ for sulfamethoxazole). However, as the urban flow was about 37 times higher than the hospital flow, the hospital contribution appeared relatively low compared to domestic discharges. Thanks to the SIPIBEL site, data obtained from this two years program are useful to evaluate the relevance of separate hospital 


\section{Introduction}

Pharmaceutically active compounds (PhAC) are specific micropollutants. They can be biologically active at very low concentrations, which imply the use of advanced analytical techniques to study their occurrence. Furthermore, beside the parent molecule, they are often excreted as metabolites that can be even more toxic than the native molecule (Pico \&Barcelo 2015). The main sources of contamination are well-known: domestic discharges, the pharmaceutical industry, healthcare facilities, releases associated with veterinary activities and fish farming, and disposal of unused medicines (Boxall et al. 2012). Nevertheless, incertitude about their relative contributions still remains. Furthermore, it is well-documented that $\mathrm{PhAC}$ are not completely removed by Conventional Activated Sludge (CAS) treatment process, which is the most used technique around the world (Noguera-Oviedo \&Aga 2016).

In the last two decades, hospital effluents have gained interest because of their high potential risk for the environment, due to their specific composition including high concentrations of PhAC, X-ray contrast media, AOX and the presence of pathogens (Carraro et al. 2016). Due to these characteristics, the assumption is often made that hospital effluents reduce the removal efficiency of wastewater treatment plants (WWTP) (Oliveira et al. 2015). Different treatment processes were studied to improve removal efficiencies of specific pollutants from hospital WW (HWW). Such additional treatments are for example Membrane Bio Reactor (MBR), the use of activated carbon and advanced oxidation processes (Verlicchi et al. 2015). However, very few investigations were performed about PhAC removal from HWWs with CAS treatment, and to the best of our knowledge, only two at full scale (Al Qarni et al. 2016, Kosma et al. 2010).

In this context, the SIPIBEL project, based on a specific WWTP whose configuration allows the study of HWW, urban WW (UWW) and their treatment separately, in the same environmental conditions, aims at an in-depth characterization of UWW and HWW and their treated effluents and the evaluation of the efficiency of a separate treatment (more details available in Chonova et al. article in this special issue). This article focuses on physicochemical characterization of WW, with the monitoring of conventional parameters, surfactants, gadolinium (Gd) and thirteen PhAC: analgesic (paracetamol, salicylic acid), antiinflammatory (ibuprofen, ketoprofen, and diclofenac), beta-blockers (atenolol, propranolol), hormonal contraceptive (ethinylestradiol), antibiotic (ciprofloxacin, sulfamethoxazole, and vancomycin), anti-fungal (econazole) and anti-convulsant (carbamazepine) products. Targeted $\mathrm{PhAC}$ were first selected according to their consumption (domestic and/or hospital) and their Persistence, Bioaccumulation and Toxicity (PBT) index, leading to a list of 62 compounds which was further reduced due to analytical and economic constraints. In order to obtain accurate data, an analytical method based on advanced techniques was developed and validated. Limits of quantification in the $\mathrm{ng} / \mathrm{L}$ range were achieved and the method was applied to the monitoring of PhAC in raw and treated WW of the SIPIBEL site, during two years. 


\section{Materials and methods}

\section{Sampling sites}

All sampling sites were located in the area of Scientrier (Haute-Savoie, France) with an average altitude between 423 and $490 \mathrm{~m}$. The weather is continental with temperatures between $-8^{\circ} \mathrm{C}$ in winter and $33^{\circ} \mathrm{C}$ in summer.

The main characteristics of the plant during the sampling period are shown in Table 1 and described in Chonova et al. (2017), in this issue. The WWTP is a low-loaded plant, designed for carbon removal and nitrification. It is equipped with pre-treatment systems including aerated grit chambers, combined with grease removers and 3 conventional activated sludge (CAS) systems: two basins of 2720 and $4000 \mathrm{~m}^{3}$, collecting UWW and one dedicated to the treatment of hospital effluents of $1280 \mathrm{~m}^{3}$ (Chonova et al. 2016). The same process, sequential aerobic and anoxic/anaerobic treatment, was applied to UWW and HWW basins. Every basin was equipped with an aeration system, proportional to the basin capacity, in order to supply the same amount of oxygen per $\mathrm{m}^{3}$-basin-capacity. Due to the low flow rate of HWW, the release of oxygen per $\mathrm{m}^{3}$ of discharge was about two times higher than in the urban basins, even if aeration times of the hospital basin were decreased to $4.4 \mathrm{~h} /$ day instead of $18 \mathrm{~h}$. The food to microorganism (F/M) ratio was between 0.1 and 0.2 $\mathrm{kgBOD}_{5} / \mathrm{kgMLVSS}^{\mathrm{d}} \mathrm{d}$ in the UWW basins and about ten times lower in the HWW basin.

The hospital effluent is separately conveyed to the WWTP and comes from a medium-sized hospital with 450 beds (1300 patients/day) and 1450 staff members. It is composed of 25 wards, including geriatrics, oncology, maternity, emergency, medical imaging, biologic analysis and kitchen (Lecomte 2016). Sterilization and laundry are outsourced. The collecting system of the hospital is separated; therefore, there should be no contribution of rain events to HWW.

Table 1 Characteristics of the WWTP

\begin{tabular}{|lccrrr}
\cline { 2 - 5 } & $\begin{array}{c}\text { WWTP capacity } \\
(\text { population equivalent / } \\
\left.\mathrm{m}^{3}\right)\end{array}$ & $\begin{array}{c}\text { Hospital } \\
\text { bed number }\end{array}$ & $\begin{array}{r}\text { Urban network } \\
\text { (inhabitants) }\end{array}$ & $\begin{array}{r}\text { Mean flow rate } \\
\left(\mathrm{m}^{3} . \text { day }^{-1}\right)\end{array}$ & $\begin{array}{r}\text { Mean HRT } \\
(\text { days })\end{array}$ \\
\hline Urban basins & $26600 \mathrm{PE} / 6720 \mathrm{~m}^{3}$ & - & 20,850 & 5355 & 1.6 \\
\hline Hospital basin & $5400 \mathrm{PE} / 1280 \mathrm{~m}^{3}$ & 450 & - & 146 & 8.1 \\
\hline
\end{tabular}

\section{Sampling}

Four sampling sites were selected: urban influent and effluent, hospital influent and effluent (more details available in Chonova et al. (2017) in this special issue). WW were sampled before pre-treatment and treated WW after the secondary treatment.

Sampling campaigns were performed between June 2013 and December 2015, during dry days, representing 27 campaigns of the hospital and urban raw WWs. Due to a change of configuration in October 2014, only 13 campaigns of the hospital and urban treated WW were achieved. Samples from all sampling sites were collected on the same days and each campaign started on Tuesday to avoid variability due to the day of sampling. Sampling was performed following approved French guidelines (Eymery et al. 2011).

To ensure representative sampling, identical sampling strategies were used for all locations. Samples were collected on a 24h-period (from 8 a.m. to 8 a.m.). 24-h composite water 
samples were collected; the sub-sampling interval was flow-proportional (with basin-specific flow volume) (Ort et al. 2010). Flows were measured before and after the WWTP. ASP Station 2000 (Endress hauser) refrigerated automated samplers were used. Both were constituted of 24 glass bottles with Teflon tubing. The content of the 24 glass bottles was gathered, mixed and homogenized. Then samples were stored in darkness at $4{ }^{\circ} \mathrm{C}$ and treated within $24 \mathrm{~h}$.

\section{Conventional physicochemical parameters}

The following physicochemical parameters of influents were analysed: 5-day biochemical oxygen demand $\left(\mathrm{BOD}_{5}\right)$, chemical oxygen demand (COD), conductivity, dissolved organic carbon (DOC), total organic carbon (TOC), $\mathrm{pH}$, total suspended solids (TSS), total phosphorus (TP), phosphates $\left(\mathrm{PO}_{4}{ }^{3-}\right)$, Kjedahl nitrogen $(\mathrm{TKN})$, ammonium $\left(\mathrm{NH}_{4}{ }^{+}\right)$, adsorbable organic halogen (AOX), Gadolinium (Gd) and cationic, non-ionic and anionic surfactants. All these parameters were analysed on the whole water except $\mathrm{DOC}, \mathrm{PO}_{4}{ }^{3-}, \mathrm{Gd}$ and cationic and anionic surfactants which were analyzed on the dissolved fraction. All these analyses were performed following standard methods (see Table S1) approved by the French organization of standardization AFNOR, except Gd which was analyzed with a validated internal method.

\section{Pharmaceutical analysis}

In order to obtain accurate data, an analytical method based on Solid Phase Extraction (SPE), Liquid Chromatography coupled with Tandem Mass Spectrometry (LC-MS/MS) and the use of isotope labelled internal standards, was developed for PhAC analysis.

\section{Chemicals and reagents}

Thirteen pharmaceuticals were analyzed: paracetamol, salicylic acid, ketoprofen, ibuprofen, diclofenac, atenolol, propranolol, econazole, ethinylestradiol, carbamazepine, and the antibiotics ciprofloxacin, sulfamethoxazole and vancomycin. All pharmaceuticals and isotopically labeled internal standards were of high purity grade (see Table S2). Individual stock standard and isotopically labeled internal standard solutions were prepared at a concentration of $200 \mathrm{mg} / \mathrm{L}$, by dissolving $2 \mathrm{mg}$ of solid reference standard in $10 \mathrm{~mL}$ of methanol. After preparation, standards were stored in the dark at $-18^{\circ} \mathrm{C}$. A mixture of these standards at $10 \mathrm{mg} / \mathrm{L}$, prepared in methanol, stored at $-18^{\circ} \mathrm{C}$ was stable for at least three months. Diluted working standard solutions were prepared regularly in water and stored at $4^{\circ} \mathrm{C}$.

LC-MS acetonitrile, methanol and acetic acid were obtained from Sigma-Aldrich (SaintQuentin Fallavier, France). Ultra-pure water was obtained with a Milli-Q water system from Millipore (Molsheim, France). SPE cartridges were Oasis HLB (60 mg, $3 \mathrm{~mL}$ ) from Waters (Milford, USA). Glass fiber filters $(0.7 \mu \mathrm{m})$ were obtained from Millipore (Molsheim, France).

\section{Sample preparation and extraction} Samples were first filtered on glass fiber filters $0.7 \mu \mathrm{m}$ with a filtration System IT30 $142 \mathrm{HW}$ from Millipore (Molsheim, France). SPE was then conducted with an AutoTrace automated 
SPE system from ThermoFisher (Roissy, France). Solid phase extraction procedure was adapted from (Gros et al. 2006). Briefly, according to the nature of water, raw WW/treated $\mathrm{WW}, 150 / 300 \mathrm{~mL}$ of filtered water samples were spiked with $150 / 120 \mu \mathrm{L}$ of a $250 \mu \mathrm{g} / \mathrm{L}$ solution of internal standards. $100 / 250 \mathrm{~mL}$ samples were then loaded at a flow rate of 10 $\mathrm{mL} / \mathrm{min}$ onto Oasis HLB cartridges previously conditioned with $5 \mathrm{~mL}$ methanol then $5 \mathrm{~mL}$ MilliQ water at $1 \mathrm{~mL} / \mathrm{min}$. Cartridges were then rinsed with $5 \mathrm{~mL}$ MilliQ water at $1 \mathrm{~mL} / \mathrm{min}$, dried $10 \mathrm{~min}$ with nitrogen and eluted with $2 \times 4 \mathrm{~mL}$ methanol at $2 \mathrm{~mL} / \mathrm{min}$. The eluates were dried with a gentle stream of nitrogen at $40{ }^{\circ} \mathrm{C}$ and reconstituted in $1 \mathrm{~mL}$ of ultra-pure water. Final extracts were transferred into $2 \mathrm{~mL}$ vials and stored at $-18^{\circ} \mathrm{C}$ prior to analysis by HPLCMS/MS. Besides, in order to analyze paracetamol and salicylic acid in raw WW, a $10 \mathrm{~mL}$ aliquot of WW filtered at $0.7 \mu \mathrm{m}$ was sampled, further filtered at $0.45 \mu \mathrm{m}$, diluted 10 times with ultra-pure water, and spiked with the internal standards solution.

\section{Liquid chromatography-tandem mass spectrometry}

Chromatographic separations were carried out with an Agilent 1290 series liquid chromatograph system (Agilent Technologies, Avondale, USA), using a Zorbax Eclipse C18 column $(50 \mathrm{~mm} \times 2.1 \mathrm{~mm}$ i.d., $1.8 \mu \mathrm{m})$ also from Agilent, protected with a KrudKatcher Ultra In-Line Filter guard column from Phenomenex (Torrence, CA, USA) were used for chromatographic separation. The column oven temperature was set at $60{ }^{\circ} \mathrm{C}$ for the positive mode and $50^{\circ} \mathrm{C}$ for the negative mode. Solvent A was Milli-Q quality water with $0.01 \%$ acetic acid and solvent B was either methanol for the positive ionization mode or acetonitrile/methanol for the negative mode. Flow rates were $0.6 \mathrm{~mL} / \mathrm{min}$ and the sample volume injected was $50 \mu \mathrm{L}$ for positive and negative modes respectively.

The LC instrument was coupled to 3200 QTrap (ABSciex, CA, USA) triple quadrupole mass spectrometer equipped with an electrospray ion source (ESI Turbo V) operated in both negative and positive modes. The quantitative analysis of the target compounds was achieved in Multiple Reaction Monitoring (MRM) mode. For quantitative purposes, two MRM transitions were monitored for each target compound. Nitrogen was used as the drying and nebulizing gas. All data were acquired and processed using Analyst 1.5.2 software. Gradient elution programs and MS/MS parameters are given in Tables S3 and S4.

\section{Quantification and quality control}

In the aim of ensuring a constant performance of the method, analytical blanks and quality controls were injected at each batch. Field blanks were also regularly performed with MilliQ water, mineral water and real water samples. In order to evaluate possible adsorption or desorption in the sampling system, undrawn and withdrawn samples were analyzed.

In order to correct for recoveries and matrix effects, internal standard calibration was performed using the stable isotope labelled analogue of each compound of interest. Indeed, internal standard calibration is one of the most accurate solutions to correct for matrix effects, as long as the internal standard co-elutes with the analyte of interest (Hewavitharana 2011). However, stronger matrix effects were observed in hospital wastewater extracts, leading to signal suppression of paracetamol and salicylic acid analogue internal standard. It is wellknown that smallest and most polar molecules are more prone to matrix effects (Taylor 2005), which is the case of paracetamol and salicylic acid. As concentrations of these two 
compounds in hospital raw wastewater were very high (superior to $100 \mathrm{ng} / \mathrm{L}$ ), wastewater, diluted by ten in MilliQ water and spiked with internal standard analogue, was injected directly in order to quantify them accurately.

Besides, in order to fully validate our analytical method, an inter-laboratory assay was conducted on surface waters (to the author's knowledge, no inter-laboratory assay was available on WW), thanks to the AGLAE association (www.association-aglae.fr). Z-scores obtained were between -0.99 for diclofenac and +1.64 for carbamazepine.

\section{Calculation methods and statistical analyses}

Mean removal efficiencies were calculated for each of the measured parameters to compare the treatment of the two lines (UWW and HWW) and the effect of the temperature on the treatment efficiency.

Furthermore, mass loadings were calculated for each sampling period by multiplying the concentrations of each compound by the mean daily flow of the respective location (hospital or urban) and sampling period. To calculate the contribution of the HWW to the total load of pollutants, first total load was calculated as a sum of hospital and urban loads. The load of each chemical in the HWW was divided by the total load of the same chemical, and multiplied by 100 . The loads of each chemical used to calculate the hospital contribution refers to the mean value of all campaigns performed. The same calculation was done for the hospital treated WW contribution to the total treated effluent in order to comprehend the effect of the treatment on the mass loadings.

Principal component analysis (PCA) was performed to present the main tendencies in the loads distribution of pharmaceuticals in urban and hospital wastewaters. Data for PCA were centered and standardized. PCA was done with R software (3.3.0, R development core team) using the ade4 package (Dray \&Dufour 2007).

\section{Results and discussion}

\section{Characterization of raw wastewaters}

\section{Conventional physico-chemical parameters, surfactants and $G d$}

Various parameters of hospital and domestic WW were followed every month during two years. Medians, minimums, maximums and coefficients of variation are reported in Table 2. 
Table 2 Conventional physico-chemical parameters, surfactants and Gd measured in hospital and urban raw wastewaters

\begin{tabular}{|c|c|c|c|c|c|c|c|c|c|}
\hline \multirow[b]{2}{*}{ Parameter } & \multicolumn{4}{|c|}{ Hospital raw WW } & \multirow[b]{2}{*}{$\begin{array}{c}\text { Median } \\
\text { ratio }\end{array}$} & \multicolumn{4}{|c|}{ Urban raw WW } \\
\hline & Median & Min & $\operatorname{Max}$ & $\begin{array}{c}\mathrm{CV} \\
\% \\
\end{array}$ & & Median & Min & $\operatorname{Max}$ & $\begin{array}{c}\mathrm{CV} \\
\% \\
\end{array}$ \\
\hline Flow $\left(\mathrm{m}^{3} /\right.$ day $)$ & 174 & 98 & 277 & 23 & 0.04 & 3892 & 2598 & 6549 & 25 \\
\hline COD (mg/L) & 918.0 & 480 & 1340 & 26 & 1.4 & 659.0 & 49 & 1698 & 52 \\
\hline Conductivity $\left(\mu \mathrm{S} / \mathrm{cm} 25^{\circ} \mathrm{C}\right)$ & 2660.0 & 2304 & 3682 & 13 & 1.8 & 1520.0 & 1079 & 1830 & 12 \\
\hline DOC (mg/L) & 116.0 & 5.9 & 178 & 47 & $\underline{2.3}$ & 50.1 & 23 & 103 & 37 \\
\hline TSS (mg/L) & 310.0 & 104 & 690 & 41 & 0.8 & 370.0 & 96 & 608 & 42 \\
\hline TP (mg/L) & 12.0 & 7.3 & 22 & 25 & 1.4 & 8.5 & 4.9 & 18 & 33 \\
\hline $\mathrm{PO}_{4}{ }^{3-}(\mathrm{mg} / \mathrm{L})$ & 7.4 & 2.3 & 9.7 & 28 & $\underline{1.9}$ & 3.8 & 2 & 7.7 & 37 \\
\hline TKN (mg/L) & 67.0 & 48.0 & 94 & 15 & 1.0 & 64.0 & 38 & 102 & 27 \\
\hline $\mathrm{NH}_{4}^{+}(\mathrm{mg} / \mathrm{L})$ & 46.0 & 16 & 70 & 23 & 1.0 & 47.0 & 23 & 86 & 26 \\
\hline $\operatorname{AOX}(\mathrm{mg} / \mathrm{L})$ & 0.69 & 0.2 & 1.7 & 44 & $\underline{14}$ & 0.05 & LOQ & 0.1 & 36 \\
\hline
\end{tabular}

254 Hospital and domestic WW presented similar values of $\mathrm{BOD}_{5}, \mathrm{COD}, \mathrm{pH}, \mathrm{TSS}, \mathrm{TP}, \mathrm{TKN}$ and

$255 \mathrm{NH}_{4}{ }^{+}$. Besides, the COD/ BOD 5 ratio of hospital and UWW were in the same range, which

256 means that they have similar biodegradability. Similar values of $\mathrm{pH}$, TKN and $\mathrm{NH}_{4}{ }^{+}$between

257 hospital and urban WW were also reported in the study of (Verlicchi et al. 2010). However,

258 such similarities of TSS were in contradiction with what is usually reported (Verlicchi et al.

259 2010). Furthermore, TSS concentrations (median of 310 and $370 \mathrm{mg} / \mathrm{L}$ for hospital and urban

$260 \mathrm{WW}$, respectively) were in the highest range of those reported in other studies (Verlicchi et al.

261 2015).

262 The other parameters were significantly different between UWW and HWW. Conductivity, $263 \mathrm{PO}_{4}{ }^{3-}$, TOC and DOC were approximately two times higher in HWW than in UWW. Even 264 more important differences were observed in concentrations of AOX and gadolinium, which

265 were more than 10 times higher in hospital WW, compared to domestic WW. As one of the main ion contributing to conductivity is chloride (Le Bonté et al. 2008), it is not surprising that the conductivity of hospital WW is higher than the one of UWW (Verlicchi et al. 2010). Concentrations of AOX are consistent with the study of Kümmerer et al. 1998. According to Kümmerer 2001, the major mass carriers for AOX in hospital wastewaters are most likely iodised X-ray contrast media, solvents, disinfectants, cleaners and drugs containing chlorine. The higher concentrations of phosphate in the hospital WW could also be explained by the release of detergents with high content of phosphorus and pharmaceuticals containing phosphoric antineoplastics from the hospital (Chonova et al. 2016). Higher DOC in hospital WW was also reported by Kovalova et al. (Kovalova et al. 2012). Gadolinium is used as a contrast agent for Magnetic Resonance Imaging (MRI), which explains its high concentrations in HWW. Values reported by Goulle et al. 2012 are consistent with our study.

Finally, global analysis of anionic and ionic surfactants revealed higher concentrations of cationic and non-ionic surfactants in HWW and higher concentrations of anionic surfactants in UWW (median concentration of $2 \mathrm{mg} / \mathrm{L}$ ). More details about the presence of surfactants are available in another article of this special issue (Bergé et al. in this issue). 
283 Concentrations of 13 pharmaceuticals in hospital and urban WW were followed every month

284 during two years. In order to avoid too high uncertainties on the results, only values superior 285 to the limit of quantification are analysed and discussed. Medians, minimums, maximums and coefficients of variation are reported in Table 3.

Table 3 Pharmaceuticals in raw hospital and urban wastewaters: limit of quantification, quantification 290 frequency, median, minimum and maximum concentration, coefficient of variation and hospital on urban median concentrations ratio (Median ratio)

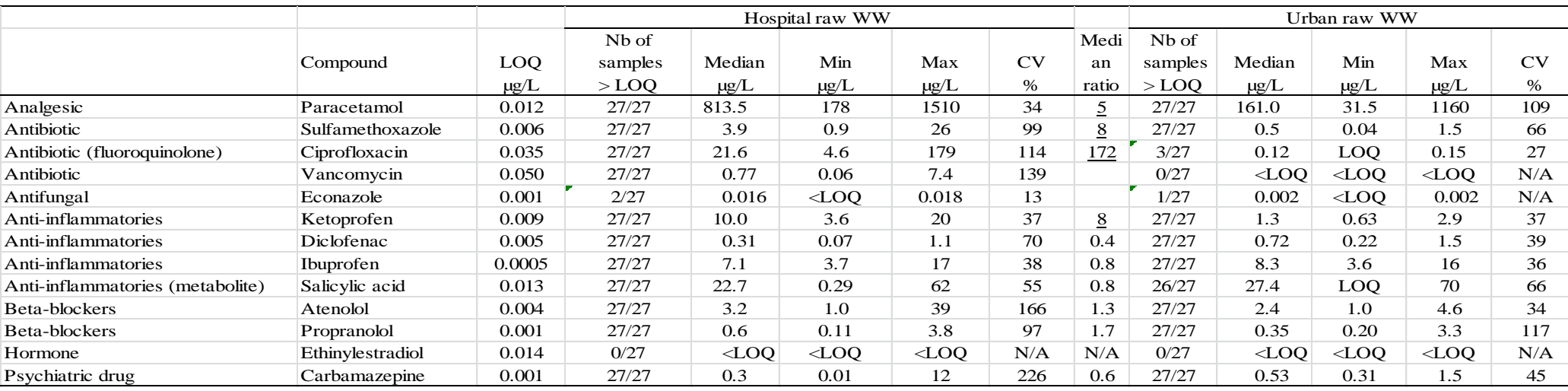

291 Ethinylestradiol was the only compound that could never be quantified during this study.

292 Econazole was only quantified once in urban raw WW and twice in hospital raw WW.

293 According to Nagarnaik et al. 2010, ethinylestradiol was also not quantified in hospital 294 effluents. This hormone is usually quantified at concentrations lower than the $\mathrm{ng} / \mathrm{L}$ range, 295 which is not detectable with our analytical method (Backe 2015). Econazole is often mainly 296 detected in the particulate phase (Lachassagne et al. 2015), which was not analyzed in this 297 work. Consequently, these two compounds are not included in the statistical analysis.

All other PhAC were quantified in $100 \%$ of the samples of HWW. Paracetamol 300 concentrations were more than ten times higher than the other PhAC, with median 301 concentrations of 813 and $161 \mu \mathrm{g} / \mathrm{L}$, in HWW and UWW respectively. Concerning HWW, all 302 other pharmaceuticals were always quantified with median concentrations varying from 0.3 303 $\mu \mathrm{g} / \mathrm{L}$ for diclofenac and carbamazepine, to $22.7 \mu \mathrm{g} / \mathrm{L}$ for salicylic acid. In UWW, the same pharmaceuticals, except ciprofloxacin and vancomycin, were always quantified with median concentrations varying from $0.35 \mu \mathrm{g} / \mathrm{L}$ for propranolol, to $27.4 \mu \mathrm{g} / \mathrm{L}$ for salicylic acid.

306 Ciprofloxacin was only quantified three times, in the order of $0.1 \mu \mathrm{g} / \mathrm{L}$, and vancomycin was 307 never quantified.

Concentrations of ibuprofen, salicylic acid, atenolol, propranolol and carbamazepine were in the same order in hospital and urban raw wastewaters. Median concentrations of diclofenac were two times lower in HWW than in UWW, but minimum and maximum concentrations were very close. All these compounds are extremely used, both in hospital and domestic sectors. Ibuprofen, salicylic acid and diclofenac belong to the 30 most sold substances in 314 urban areas of France (Cavalié 2014). Atenolol and propranolol use is more restricted but these high concentrations can be explained by the increase in the average age of the 
population and the presence of retirement homes in the catchment area. Conversely, concentrations of two painkillers (paracetamol, ketoprofen) and three antibiotics (sulfamethoxazole, ciprofloxacin, vancomycin) were significantly higher in HWW than in UWW. Higher concentrations in hospital WW of these compounds were also reported by Al Aukidy et al. 2014 which reviewed pharmaceutical concentrations in hospital and urban WW. Paracetamol is the most prescribed analgesic: its higher concentration in hospital WW can be explained by the higher proportion of injured people at the hospital. Contrary to the other antiinflammatories (ibuprofen, salicylic acid and diclofenac), ketoprofen is only accessible by prescription, and so more used in the hospital sector. Finally, high concentrations of antibiotics in hospital WW, compare to domestic WW, have already been reported (Tuc et al. 2017). Vancomycin, which is restricted to hospital use, was only detected in hospital WW, whereas sulfamethoxazole and ciprofloxacin were quantified in both WW, but in concentrations respectively 10 and 100 times higher in hospital WW.

\section{Removal efficiencies}

Regarding the conventional parameters, removals were very high in both WW lines, hospital and urban. Median removal of TSS, COD, $\mathrm{BOD}_{5}$ and $\mathrm{NH}_{4}{ }^{+}$were respectively $99 \%$, 98\%, $100 \%$ and $99-100 \%$. These values show effective carbon removal and nitrification in UWW and HWW lines, which meet the standard guidelines given by the Water Framework Directive (WFD) (European commission, 1991). The WWTP is not designed for denitrification, which leads to remaining median concentrations of $\mathrm{NO}_{3}{ }^{-}$of 1.3 and $10.4 \mathrm{mg} / \mathrm{L}$ and $\mathrm{NO}_{2}{ }^{-}$of 0.1 and $0.03 \mathrm{mg} / \mathrm{L}$ in urban and hospital treated WW, respectively.

Numerous parameters can affect removal efficiency: solid retention time (SRT), HRT, temperature, $\mathrm{pH}$, nitrification and redox conditions (Falas et al. 2016). In this study, $\mathrm{pH}$ and temperature of urban and hospital WW were similar for both basins, but this was not the case for HRT and redox conditions. The HRT in the HWW line was around five times higher than in the UWW line. Furthermore, due to the low hospital discharge, the release of oxygen per $\mathrm{m} 3$ of discharge was about two times higher than in the urban basins, which may explain the higher concentrations of nitrate in the hospital basin. These particular operational conditions and the presence of antibiotics and biocides (Bergé et al. in this issue) in the HWW may influence the growth and structure of bacterial communities, as demonstrated by Chonova et al. 2016.

Concerning pharmaceuticals, removal efficiencies were between 75 and $100 \%$ in the HWW line and between 30 and 100\% in the UWW line, except for carbamazepine (Table 4). These removals were generally higher compared to studies reporting HRT below 24h (Verlicchi et al., 2012b). Higher HRT for the WWTP studied here, may explain higher removal, especially for certain molecules (e.g. ibuprofen) (Kosma et al., 2010). The removal efficiency varied strongly depending on the molecule. Removals of paracetamol, salicylic acid, ibuprofen, ketoprofen, atenolol and the antibiotics ciprofloxacin and vancomycin were higher than $90 \%$, whereas the remaining four pharmaceuticals propranolol, 
Carbamazepine and diclofenac even exhibited higher concentrations in the treated effluents, than in the raw wastewaters. These negative removals were not regular regarding diclofenac, but very frequent concerning carbamazepine, which explains why its removal rates could not be calculated (Table 4). This phenomenon for carbamazepine has already been reported in several studies (e.g. Radjenović et al., 2009).

Table 4 Pharmaceuticals in treated hospital and urban wastewaters: limit of quantification, quantification frequency, median, minimum and maximum concentration, coefficient of variation, median removal and associated coefficient of variation

\begin{tabular}{|c|c|c|c|c|c|c|c|c|c|c|c|c|c|c|c|c|}
\hline \multirow[b]{2}{*}{ Compound } & \multirow[b]{2}{*}{$\begin{array}{c}\mathrm{LOQ} \\
\mathrm{ng} / \mathrm{L}\end{array}$} & \multicolumn{7}{|c|}{ Hospital treated WW } & \multicolumn{7}{|c|}{ Urban treated WW } & \multirow[b]{2}{*}{$\begin{array}{r}\text { Removal } \\
\text { range }^{\mathrm{a}} \\
(\%) \\
\end{array}$} \\
\hline & & $\begin{array}{c}\mathrm{Nb} \text { of } \\
\text { samples } \\
>\text { LOQ }\end{array}$ & $\begin{array}{c}\text { Median } \\
\mathrm{ng} / \mathrm{L}\end{array}$ & $\begin{array}{l}\mathrm{Min} \\
\mathrm{ng} / \mathrm{L}\end{array}$ & $\begin{array}{l}\mathrm{Max} \\
\mathrm{ng} / \mathrm{L}\end{array}$ & $\begin{array}{c}\mathrm{CV} \\
\%\end{array}$ & $\begin{array}{r}\text { Median } \\
\text { Removal } \\
\%\end{array}$ & $\begin{array}{c}\mathrm{CV} \\
\%\end{array}$ & $\begin{array}{c}\mathrm{Nb} \text { of } \\
\text { samples } \\
>\text { LOQ }\end{array}$ & $\begin{array}{c}\text { Median } \\
\mathrm{ng} / \mathrm{L}\end{array}$ & $\begin{array}{c}\mathrm{Min} \\
\mathrm{ng} / \mathrm{L}\end{array}$ & $\begin{array}{l}\mathrm{Max} \\
\mathrm{ng} / \mathrm{L}\end{array}$ & $\begin{array}{c}\mathrm{CV} \\
\%\end{array}$ & $\begin{array}{r}\text { Median } \\
\text { Removal } \\
\%\end{array}$ & $\begin{array}{c}\mathrm{CV} \\
\%\end{array}$ & \\
\hline Paracetamol & 12.2 & $8 / 13$ & 39.0 & $<\mathrm{LOQ}$ & 3272 & 180 & 100.0 & 0.2 & $9 / 13$ & 69.4 & $<\mathrm{LOQ}$ & 714 & 78 & 99.9 & 0.1 & $80-99$ \\
\hline Sulfamethoxazole & 5.9 & $13 / 13$ & 810.0 & 79.4 & 1514 & 68 & 75.3 & 33 & $12 / 13$ & 119.5 & $<\mathrm{LOQ}$ & 1004 & 148 & 73.1 & 87 & $10-99$ \\
\hline Ciprofloxacine & 35.3 & $8 / 13$ & 363.5 & $<\mathrm{LOQ}$ & 3414 & 138 & 99.2 & 2.4 & $2 / 13$ & 95.1 & $<$ LOQ & 144 & 73 & 94.3 & 1.0 & $18-96$ \\
\hline Vancomycin & 50.0 & $4 / 13$ & 27.6 & $<\mathrm{LOQ}$ & 49 & 44 & 98.6 & 6.3 & $0 / 13$ & $<\mathrm{LOQ}$ & $<\mathrm{LOQ}$ & $<$ LOQ & $<\mathrm{LOQ}$ & N/A & N/A & $10^{\mathrm{b}}$ \\
\hline Ketoprofen & 9.3 & $11 / 13$ & 36.0 & $<\mathrm{LOQ}$ & 83 & 55 & 100.0 & 0.2 & $13 / 13$ & 84.0 & 22 & 397 & 90 & 91.0 & 12 & $7-92$ \\
\hline Diclofenac & 5.0 & $13 / 13$ & 76.0 & 18 & 874 & 170 & 77.0 & 23 & $13 / 13$ & 488.0 & 42 & 790 & 50 & 30.3 & 113 & $3-80$ \\
\hline Ibuprofen & 0.5 & $11 / 13$ & 30.0 & $<\mathrm{LOQ}$ & 88 & 79 & 99.7 & 0.3 & $11 / 13$ & 96.0 & $<\mathrm{LOQ}$ & 356 & 92 & 98.9 & 1.6 & $26-99$ \\
\hline Salicylic acid & 13.3 & $1 / 13$ & 114.0 & $<\mathrm{LOQ}$ & 114 & N/A & 100.0 & 0.2 & $1 / 13$ & 138.0 & $<\mathrm{LOQ}$ & 138 & N/A & 100.0 & 1.6 & $97-99$ \\
\hline Atenolol & 4.1 & $7 / 13$ & 18.8 & 13.6 & 146 & 94 & 99.7 & 1.8 & $13 / 13$ & 193.0 & 8.16 & 552 & 74 & 91.0 & 8.9 & $14-85$ \\
\hline Propranolol & 0.6 & $13 / 13$ & 112.0 & 22 & 242 & 56 & 87 & 10 & $13 / 13$ & 110.0 & 23 & 236 & 57 & 70.0 & 42 & $1-96$ \\
\hline Carbamazepine & 0.6 & $13 / 13$ & 629.0 & 133 & 1334 & 48 & - & - & $13 / 13$ & 498.0 & 231 & 788 & 29 & - & - & 5-78 \\
\hline
\end{tabular}

Main removal mechanisms of micropollutants are biodegradation/biotransformation, sorption and volatilization. As pharmaceuticals selected for this study are almost not volatile, the last one is expected to be of minor importance. The increase of certain molecules in the treated effluents may be due to their excretion as conjugate metabolites in raw WW, which were not analyzed and may be transformed into the parent compound after treatment. This has already been observed for carbamazepine (Bouju et al. 2016), diclofenac (Bouju et al. 2016) and sulfamethoxazole (Guerra et al. 2014, Verlicchi et al. 2015). Other reason may be the sampling procedure. Samples from raw WW and treated effluents were taken in the same day; hence HRT was not taken into account. This is of particular importance for the hospital WW where the mean HRT was 8 days.

Differences in removal efficiency between molecules were already reported (Verlicchi et al. 2012b). As confirmed in our study, paracetamol, salicylic acid and ibuprofen are highly biodegradable molecules. We also observed good removals of ciprofloxacin. However, these can also be explained by the high capacity of this molecule to adsorb to sludge - about $60 \%$ (Zhou et al. 2013). Regarding the other pharmaceuticals, removals were relatively lower, especially in the case of the UWW treatment. Differences were observed for example, considering ketoprofen and diclofenac removals: in the UWW line, ketoprofen removal was a little lower and diclofenac removal decreased dramatically compared to HWW line. Reported values of removals of ketoprofen and diclofenac are very variable through the literature and may increase with higher HRT, SRT, temperature and with reactors that include nitrification and denitrification steps. Consequently, the higher HRT of the HWW line (8 days) is one possible explanation of good removals obtained for diclofenac and ketoprofen. This 
difference can also be explained by the higher concentration of nitrates in the hospital basin. Indeed, Barbieri et al. 2012 demonstrated the formation of the nitro derivative of diclofenac, which can be retransformed to the parent compound. Hence, the higher removal in the HWW basin may reflect a higher transformation of diclofenac into nitro-diclofenac and not its biodegradation (Chonova et al. 2016). A great variability in the removals of the beta-blockers atenolol and propranolol was also observed in the literature (Table 4). In our study, removals of atenolol and propranolol were a bit lower in the UWW line, than in the HWW line. Stadler et al. 2015 studied the effect of redox conditions on pharmaceutical removals and observed higher removal of atenolol under fully aerobic conditions. This also highlights the importance of oxygenation for the removal efficiency of certain molecules and difference in the removal efficiency between urban and hospital line. Another important parameter that influences the removal of micropollutants is the F/M ratio. Petrie et al. 2014 observed a good correlation between the decrease of the $\mathrm{F} / \mathrm{M}$ ratio from 0.25 to $0.05 \mathrm{kgBOD} / \mathrm{kgMLVSS}$.d and the increase of the removal of estrogens. Indeed, a low F/M ratio implies a limitation of the substrate available for microorganisms, which may lead to the biodegradation of less easily assimilable carbon substrates.

Finally, an important variability of the removal efficiency (Coefficient of Variation $>40 \%$ ) was observed in the UWW line, compared to the HWW line. This may be explained by the lower volume of WW discharged in the hospital basin (Kosma et al. 2010) and by larger variation of contamination sources and stronger seasonal fluctuations in UWW. Seasonal differences in removal efficiency, linked to changes in the ambient temperature, were also observed. However, this trend was only visible in the urban basin. Removal efficiency of the following molecules showed significant decrease during colder months: atenolol, diclofenac, ibuprofen, ketoprofen and propranolol (Figure 1). For example, diclofenac removal was very variable throughout seasons, with a mean removal of 55\% in warmer months, and only $1 \%$ in colder months. The same effect of temperature was observed regarding $\mathrm{NH}_{4}^{+}$removal. Indeed, nitrifying bacteria growth is dependent on temperature and temperature sensitivity decreases with increasing SRT (Willers et al. 1993) which may explain why it was only observed in the urban line. 

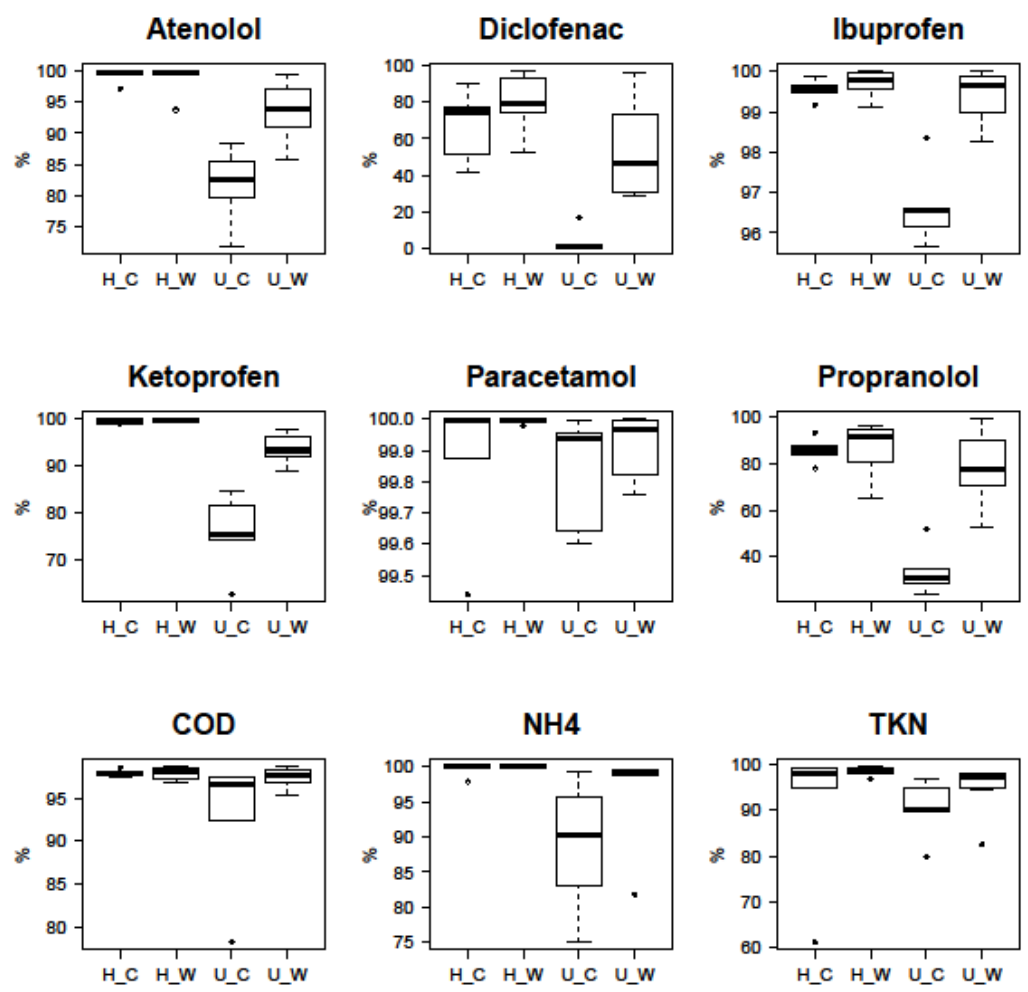

Fig. 1 - Boxplots presenting removal rates of some pharmaceuticals and physico-chemical parameters in hospital $(\mathrm{H})$ and Urban $(\mathrm{U})$ lines during colder $\left(\_\mathrm{c}\right)\left(<14^{\circ} \mathrm{C}\right)$ and warmer $\left(\_w\right)\left(>14^{\circ} \mathrm{C}\right)$ months (in \%)

\section{Concentrations of pharmaceuticals in treated WW}

Eleven molecules out of the thirteen monitored pharmaceuticals were quantified in hospital and/or urban treated wastewaters: paracetamol, sulfamethoxazole, ciprofloxacin, vancomycin, ketoprofen, diclofenac, ibuprofen, salicylic acid, atenolol, propranolol and carbamazepine. Median concentrations (Table 4) ranged between $19 \mathrm{ng} / \mathrm{L}$ for atenolol and $810 \mathrm{ng} / \mathrm{L}$ for sulfamethoxazole in HWW. Median concentrations of carbamazepine, which is well-known to be resistant to treatments (Chonova et al. 2016, Radjenovic et al. 2009), were also significant with 629 and $498 \mathrm{ng} / \mathrm{L}$, in HWW and UWW, respectively. These concentrations found in treated WW are consistent with the literature (Al Qarni et al. 2016, Santos et al. 2013, Verlicchi et al. 2012b)

Six pharmaceuticals were quantified in more than $80 \%$ of the samples: sulfamethoxazole, ketoprofen, diclofenac, ibuprofen, propranolol and carbamazepine. Regarding differences between hospital and urban treated WW, despite a good removal efficiency of the treatment, antibiotics concentrations remained higher in hospital effluents than in urban ones. Conversely, atenolol and three anti-inflammatories (ketoprofen, diclofenac and ibuprofen) were found in higher concentrations in the domestic treated WW.

\section{Loads and contributions}

Loads of pharmaceuticals were calculated to reveal the effect of the amount of discharge on the quantity of micropollutants released with the urban and the hospital WW. PCA performed 
to present these loads shows that urban and hospital samples have very different characteristics according to the loads of pollutants since they are placed oppositely on the first axis (Fig. 2). Exceptions are the pharmaceuticals vancomycin and ciprofloxacin, which are more associated to the second axis. Vancomycin and ciprofloxacin are hospital tracers which were not regularly detected in UWW (Table 3). This may explain the higher importance of their loads in the HWW comparing to other pharmaceuticals. Furthermore, despite higher concentrations of certain compounds in the HWW, UWW are characterized by higher loads of almost all compounds. This is caused by the different amount of discharge: the urban discharge is more than 37 times higher than the hospital discharge. These data confirm that, except for antibiotics, UWW are the dominant emission pathway of pharmaceuticals (der Beek et al. 2016). Indeed, high concentrations of pharmaceuticals are released by health-care facilities. However, their regular quantification in UWW is an evidence for their constant consumption at home as well.

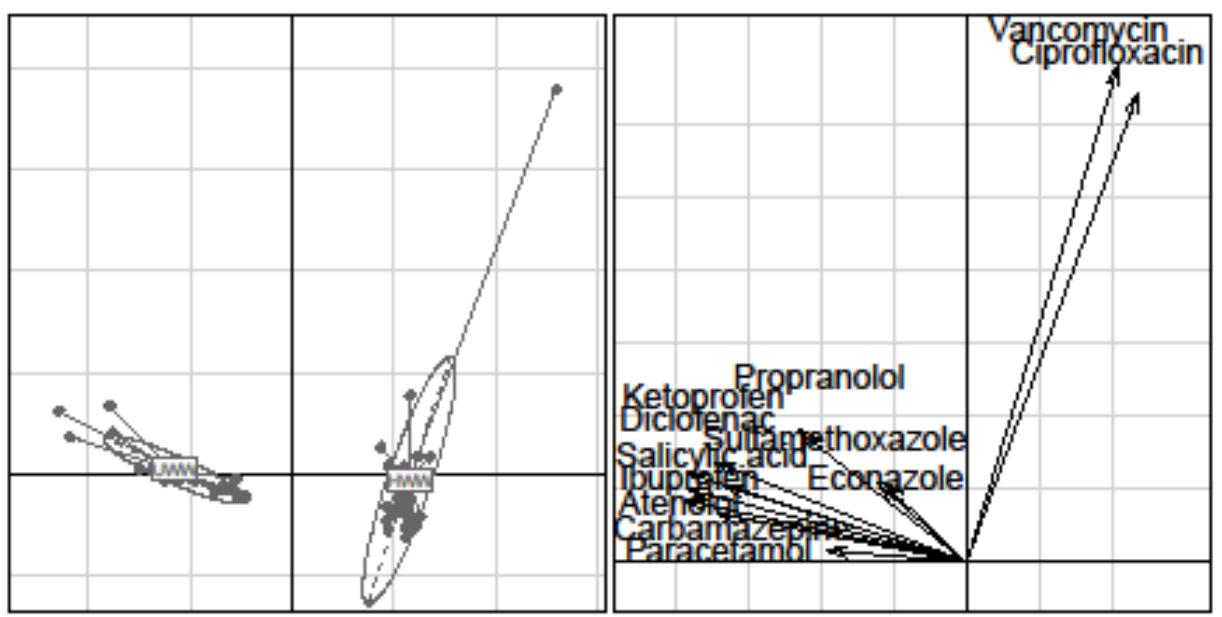

Fig. 2 - PCA based on loads of pharmaceuticals parameters in the locations UWW and HWW (the first two axes represent respectively $50 \%$ and $12 \%$ of the variability)

Besides, monthly campaigns showed great variability of concentrations and loads, both in hospital and urban WW, with coefficients of variation up to $200 \%$. An example is shown in Figure 3, for sulfamethoxazole. An increase of sulfamethoxazole load of hospital WW can be observed in autumn 2014 and 2015, which can be attributed to an increase in consumption during these periods. A higher variation of the HWW load compared to the UWW load is observed, which can be explained by the small number of patients compared to the large number of people taking pharmaceuticals at home (Ort et al. 2010). Apart from this case, no seasonality was observed for the other compounds both in urban and hospital WW, which is in accordance with Kosma et al. 2010 (Kosma et al. 2010). This is in contradiction with other studies (Fernández et al. 2014, Yu et al. 2013) which reported higher concentrations in winter. However they present shorter monitoring period (1 year), lower number of sampling campaigns and the WWTP studied were significantly larger. Fernández et al. 2014 also studied the seasonality of PhC concentrations in WW and found no tendency. 


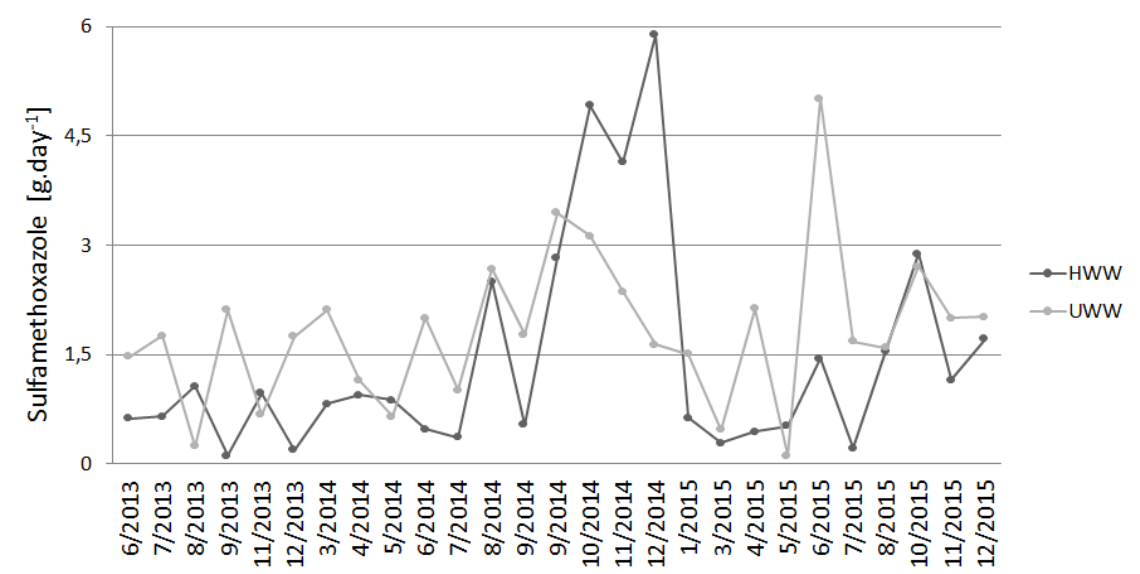

Fig. 3 - Evolution of the load of sulfamethoxazole through SIPIBEL campaigns in hospital and urban wastewaters

Finally, contributions of hospital and urban micropollutants to the total load of micropollutants in raw and treated WW were calculated to evaluate the importance of hospital WW concerning the input of pollutants (Figure 4). Hospital contribution to the total load of raw WW is higher than $10 \%$ for Gd (45\%), AOX (40\%), paracetamol (15\%), ketoprofen (28\%) and the antibiotics sulfamethoxazole (34\%), ciprofloxacin (99\%) and vancomycin $(100 \%)$. These values are relatively high compared to the literature (Azuma et al. 2016, Kleywegt et al. 2016, Ort et al. 2010, Santos et al. 2013). First, the percentage that represents the hospital flow to the total flow of the WWTP is quite high (3\%), whereas this ratio is lower in the other studies: between $0.2 \%$ in Kleywegt et al. 2016 study and 2\% in Santos et al. 2013. Nevertheless, paracetamol, ketoprofen and sulfamethoxazole contributions are consistent with Santos et al. 2013. Secondly, the urban network of our study is collecting WW from about 20,850 inhabitants, which represents a bed density (number of beds per 1,000 inhabitants) of 21.6. Hospital bed densities in developed countries are usually around 5 beds per 1,000 inhabitants (Ort et al. 2010). Verlicchi et al. 2012a compared studies with bed density between 4 and 33.5: logically, the highest contributions were found in the case of the highest bed density. Finally, high contributions of vancomycin and ciprofloxacin are explained by the fact that these substances were respectively never quantified and quantified only in $10 \%$ of the samples in UWW. After treatment, thanks to good overall removal efficiency, hospital contribution is higher than $10 \%$ only for $\mathrm{Gd}(79 \%)$, AOX (24\%), and the antibiotics sulfamethoxazole (14\%), ciprofloxacin (52\%). 

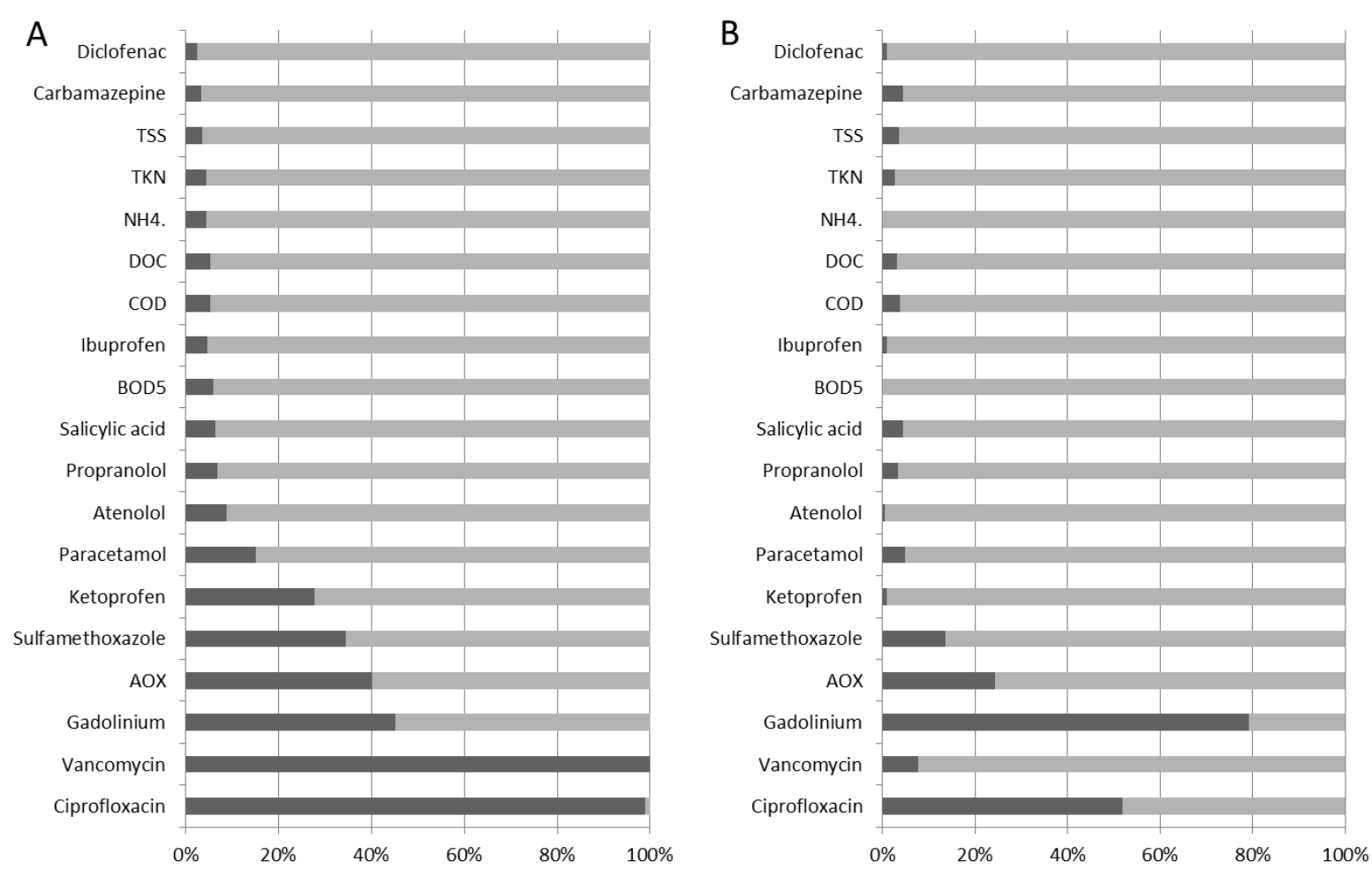

Fig. 4 - Hospital (black) and urban (grey) contributions of conventional parameters and pharmaceuticals to total load of pollutants in A: wastewaters and B: treated effluents

\section{Conclusion}

This article presents the results of a two years regular monitoring of conventional physicochemical parameters and thirteen $\mathrm{PhAC}$ of various classes, in urban and hospital raw wastewaters and their treated effluents. With the help of accurate sampling strategies and the use of advanced analytical techniques, an in-depth characterization of hospital and urban WW was performed. Organic carbon, AOX, phosphates, Gadolinium and the pharmaceuticals paracetamol, ketoprofen and antibiotics were found in higher concentrations in hospital effluents. After activated sludge treatment, only concentrations of antibiotics were still higher in hospital effluents. Nevertheless, due to a significantly higher flow from the urban catchment, despite higher concentrations for certain compounds in hospital WW, hospital contribution of PhAC was lower than domestic contribution. Finally, even if hospital and urban WW were treated in the same geographical environment, differences in removal efficiencies were observed, which may be due to various factors: the specific composition of the hospital WW, hydraulic retention time and redox conditions. 


\section{Acknowledgements}

530 The authors thank the SIPIBEL field observatory on hospital's effluents and urban wastewater 531 treatment plants for displaying data and measurements and the European Union, the Rhone532 Mediterranean Corsica water agency, the Rhône Alpes Region, ONEMA and the French 533 Ministry of Environment for their support.

534

535 
Al Aukidy M, Verlicchi P, Voulvoulis N (2014) A framework for the assessment of the environmental risk posed by pharmaceuticals originating from hospital effluents. Science of the Total Environment 493:54-64

Al Qarni H, Collier P, O'Keeffe J, Akunna J (2016) Investigating the removal of some pharmaceutical compounds in hospital wastewater treatment plants operating in Saudi Arabia. Environmental Science and Pollution Research 23:13003-13014

Azuma T, Arima N, Tsukada A, Hirami S, Matsuoka R, Moriwake R, Ishiuchi H, Inoyama T, Teranishi Y, Yamaoka M, Mino Y, Hayashi T, Fujita Y, Masada M (2016) Detection of pharmaceuticals and phytochemicals together with their metabolites in hospital effluents in Japan, and their contribution to sewage treatment plant influents. Science of the Total Environment 548:189-197

Backe WJ (2015) An Ultrasensitive (Parts-Per-Quadrillion) and SPE-Free Method for the Quantitative Analysis of Estrogens in Surface Water. Environmental Science \& Technology 49:14311-14318

Barbieri M, Carrera J, Ayora C, Sanchez-Vila X, Licha T, Nodler K, Osorio V, Perez S, Kock-Schulmeyer M, de Alda ML, Barcelo D (2012) Formation of diclofenac and sulfamethoxazole reversible transformation products in aquifer material under denitrifying conditions: Batch experiments. Science of the Total Environment 426: 256-263

Bergé A, Wiest L, Giroud B, Baudot R, Vulliet E, Occurrence of multi-class surfactants in urban wastewater: contribution of a healthcare facility to the pollution transported into the sewerage system, submitted

Bouju H, Nastold P, Beck B, Hollender J, Corvini PFX, Wintgens T (2016) Elucidation of biotransformation of diclofenac and 4 hydroxydiclofenac during biological wastewater treatment. Journal of Hazardous Materials 301:443-452

Boxall ABA et al. (2012) Pharmaceuticals and Personal Care Products in the Environment: What Are the Big Questions? Environmental Health Perspectives 120:1221-1229

Carraro E, Bonetta S, Bertino C, Lorenzi E, Gilli G (2016) Hospital effluents management: Chemical, physical, microbiological risks and legislation in different countries. Journal of Environmental Management 168:185-199

Cavalié P (2014) Analyse des ventes de médicaments en France en 2013. http://www.ansm.fr

Chonova T, Keck F, Labanowski J, Montuelle B, Rimet F, Bouchez A (2016) Separate treatment of hospital and urban wastewaters: A real scale comparison of effluents and their effect on microbial communities. Science of the Total Environment 542:965-975

Chonova T, Lecomte V, Bertrand-Krajewski J-L, Dagot C, Lévi Y, Perrodin Y, Labanowski J, Wiest L, Gonzalez-Ospina A, Bouchez A, Cournoyer B, Sebastian C (2017) The SIPIBEL project: treatment of both hospital and urban wastewater in a conventional urban wastewater treatment plant, Environmental Science and Pollution Research, accepted

Der Beek TA, Weber FA, Bergmann A, Hickmann S, Ebert I, Hein A, Kuster A (2016) Pharmaceuticals in the environment-global occurrences and perspectives. Environmental Toxicology and Chemistry 35:823-835

Dray S, Dufour AB (2007) The ade4 package: Implementing the duality diagram for ecologists. Journal of Statistical Software 22:1-20

European Commission (1991) Directive 91/271/EEC of the council of the European communities of 21 st May 1991 concerning urban waste water treatment to protect the water environment from the adverse effects of discharges of urban waste water and from certain industrial discharges. Off. J. Eur. Communities 135:40-52. 
Eymery F, Choubert J-M, Lepot B, Gasperi J, Lachenal J, Coquery M (2011) Guide technique opérationnel : Pratiques d'échantillonnage et de conditionnement en vue de la recherche de micropolluants prioritaires et émergents en assainissement collectif et industriel, Première version. Irstea/Cemagref

Falas P, Wick A, Castronovo S, Habermacher J, Ternes TA, Joss A (2016) Tracing the limits of organic micropollutant removal in biological wastewater treatment. Water Research 95:240-249

Fernández M, Fernández M, Laca A, Laca A, Diaz M (2014) Seasonal occurrence and removal of pharmaceutical products in municipal wastewaters. Journal of Environmental Chemical Engineering 2:495-502

Goulle JP, Saussereau E, Mahieu L, Cellier D, Spiroux J, Guerbet M (2012) Importance of Anthropogenic Metals in Hospital and Urban Wastewater: Its Significance for the Environment. Bulletin of Environmental Contamination and Toxicology 89:12201224

Gros M, Petrovic M, Barcelo D (2006) Development of a multi-residue analytical methodology based on liquid chromatography-tandem mass spectrometry (LCMS/MS) for screening and trace level determination of pharmaceuticals in surface and wastewaters. Talanta 70:678-690

Guerra P, Kim M, Shah A, Alaee M, Smyth SA (2014) Occurrence and fate of antibiotic, analgesic/anti-inflammatory, and antifungal compounds in five wastewater treatment processes. Science of the Total Environment 473:235-243

Kleywegt S, Pileggi V, Lam YM, Elises A, Puddicomb A, Purba G, Di Caro J, Fletcher T (2016) The contribution of pharmaceutically active compounds from healthcare facilities to a receiving sewage treatment plant in canada. Environmental Toxicology and Chemistry 35:850-862

Kosma CI, Lambropoulou DA, Albanis TA (2010) Occurrence and removal of PPCPs in municipal and hospital wastewaters in Greece. Journal of Hazardous Materials 179:804-817

Kovalova L, Siegrist H, Singer H, Wittmer A, McArdell CS (2012) Hospital Wastewater Treatment by Membrane Bioreactor: Performance and Efficiency for Organic Micropollutant Elimination. Environmental Science \& Technology 46:1536-1545

Kummerer K, Erbe T, Gartiser S, Brinker L (1998) AOX emissions from hospital into municipal wastewater. Chemosphere 36:2437-2445

Kummerer K (2001) Drugs in the environment: emission of drugs, diagnostic aids and disinfectants into wastewater by hospitals in relation to other sources - a review. Chemosphere 45:957-969

Lachassagne D, Soubrand M, Casellas M, Gonzalez-Ospina A, Dagot C (2015) Impact of sludge stabilization processes and sludge origin (urban or hospital) on the mobility of pharmaceutical compounds following sludge landspreading in laboratory soil-column experiments. Environmental Science and Pollution Research 22:17135-17150

Lecomte V (2016) Rapport SIPIBEL 2011-2015 : résultats de quatre années de suivi, d'études et de recherches, sur le site pilote de Bellecombe, accessed in www.graie.org/Sipibel/publications

Le Bonté S, Pons M-N, Potier O, Rocklin P (2008) Relation Between Conductivity and Ion Content in Urban Wastewater. Revue des sciences de l'eau 21:429-438

Nagarnaik PM, Mills MA, Boulanger B (2010) Concentrations and mass loadings of hormones, alkylphenols, and alkylphenol ethoxylates in healthcare facility wastewaters. Chemosphere 78:1056-1062 
Noguera-Oviedo K, Aga DS (2016) Lessons learned from more than two decades of research on emerging contaminants in the environment. Journal of Hazardous Materials 316:242-251

Oliveira TS, Murphy M, Mendola N, Wong V, Carlson D, Waring L (2015) Characterization of Pharmaceuticals and Personal Care products in hospital effluent and waste water influent/effluent by direct-injection LC-MS-MS. Science of the Total Environment 518:459-478

Ort C, Lawrence MG, Reungoat J, Eaglesham G, Carter S, Keller J (2010) Determining the fraction of pharmaceutical residues in wastewater originating from a hospital. Water Research 44:605-615

Petrie B, McAdam EJ, Lester JN, Cartmell E (2014) Assessing potential modifications to the activated sludge process to improve simultaneous removal of a diverse range of micropollutants. Water Research 62:180-192

Pico Y, Barcelo D (2015) Transformation products of emerging contaminants in the environment and high-resolution mass spectrometry: a new horizon. Analytical and Bioanalytical Chemistry 407:6257-6273

Radjenovic J, Petrovic M, Barcelo D (2009) Fate and distribution of pharmaceuticals in wastewater and sewage sludge of the conventional activated sludge (CAS) and advanced membrane bioreactor (MBR) treatment. Water Research 43:831-841

Santos LHMLM, Gros M, Rodriguez-Mozaz S, Delerue-Matos C, Pena A, Barcelo D, Montenegro MCBSM (2013) Contribution of hospital effluents to the load of pharmaceuticals in urban wastewaters: Identification of ecologically relevant pharmaceuticals. Science of the Total Environment 461:302-316

Stadler LB, Su LJ, Moline CJ, Ernstoff AS, Aga DS, Love NG (2015) Effect of redox conditions on pharmaceutical loss during biological wastewater treatment using sequencing batch reactors. Journal of Hazardous Materials 282:106-115

Taylor PJ (2005) Matrix effects: The Achilles heel of quantitative high-performance liquid chromatography-electrospray-tandem mass spectrometry. Clinical Biochemistry 38:328-334

Tuc DQ, Elodie MG, Pierre L, Fabrice A, Marie-Jeanne T, Martine B, Joelle E, Marc C (2017) Fate of antibiotics from hospital and domestic sources in a sewage network. Science of the Total Environment 575: 758-766

Verlicchi P, Galletti A, Petrovic M, Barcelo D (2010) Hospital effluents as a source of emerging pollutants: An overview of micropollutants and sustainable treatment options. Journal of Hydrology 389:416-428

Verlicchi P, Al Aukidy M, Galletti A, Petrovic M, Barcelo D (2012a) Hospital effluent: Investigation of the concentrations and distribution of pharmaceuticals and environmental risk assessment. Science of the Total Environment 430: 109-118

Verlicchi P, Al Aukidy M, Zambello E (2012b) Occurrence of pharmaceutical compounds in urban wastewater: Removal, mass load and environmental risk after a secondary treatment-A review. Science of the Total Environment 429: 123-155

Verlicchi P, Al Aukidy M, Zambello E (2015) What have we learned from worldwide experiences on the management and treatment of hospital effluent? - An overview and a discussion on perspectives. Science of the Total Environment 514:467-491

Willers HC, Tenhave PJW, Derikx PJL, Arts MW (1993) Temperature-dependency of nitrification and required anoxic volume for denitrification in the biological treatment of veal calf manure. Bioresource Technology 43:47-52

Yu Y, Wu L, Chang AC (2013) Seasonal variation of endocrine disrupting compounds, pharmaceuticals and personal care products in wastewater treatment plants. Science of the Total Environment 442:310-316 
Zhou XF, Zhang YL, Shi L, Chen JB, Qiang ZM, Zhang TC (2013): Partitioning of Fluoroquinolones on Wastewater Sludge. Clean-Soil Air Water 41, 820-827

\section{Figure captions}

Figure 1: Boxplots presenting comparison of removal rates of pharmaceuticals and other physico-chemical parameters in hospital $(\mathrm{H})$ and Urban $(\mathrm{U})$ during colder (_c) $\left(<14^{\circ} \mathrm{C}\right)$ and warmer (_w) $\left(>14^{\circ} \mathrm{C}\right)$ months (in \%)

Figure 2: PCA based on loads of pharmaceuticals parameters in the locations UWW and HWW (the first two axes represent respectively $50 \%$ and $12 \%$ of the variability)

Figure 3 : Evolution of the load of sulfamethoxazole through SIPIBEL campaigns in hospital and urban wastewaters

Figure 4: Hospital (black) and urban (grey) contributions of conventional parameters and pharmaceuticals to total load of pollutants in A: wastewaters and B: treated effluents 